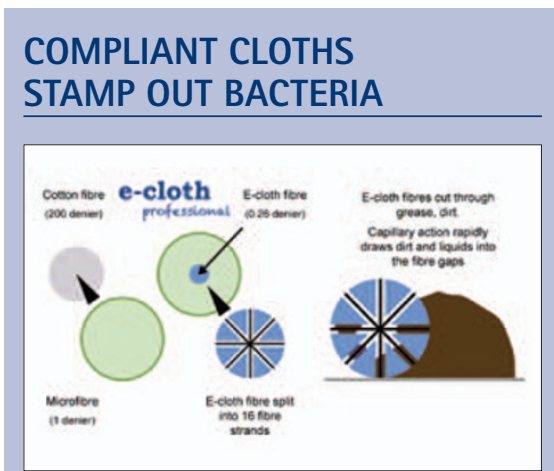

Evident's range of re-usable, washable microfibre cloths, 'e-cloth Professional', contain antibacterial nano-silver and clean so effectively that there is nowhere left for bacteria to grow, removing grease, dirt and bacteria from hard surfaces without the need for harsh, needlessly expensive cleaning products.

HTM 01-05 section 6.58 details Department of Health sponsored research on the use of microfibre cloths suggesting that, provided deep cleaning is performed as an initial exercise, the subsequent use of microfibre-based techniques can be helpful in achieving satisfactory removal of infectious agents from surfaces. Additionally it states, 'The patient treatment areas should be cleaned after every session using disposable cloths or clean microfibre materials'.

Following National Patient Safety Agency guidelines 'e-cloth Professional' cloths are available in packs of ten in green, blue, red or yellow.

Reader response number 54

\title{
STANDARD CONTRACT FOR SALE AND PURCHASE
}

The lawyers at the National

Association of Specialist Dental

Accountants \&t Lawyers (NASDAL)

have created a standard contract

for the sale and purchase of dental practices with the aim of reducing stress for dentists on both sides of a negotiation. From 2012, any sale agreement with a NASDAL lawyer on both sides should be completed more easily.

Buying and selling a dental practice has become a time-consuming and unpredictable process which can typically take up to five months, due to banks being slower and more cautious and because dealing with the Care Quality Commission (CQC) is causing long delays. By creating a standard contract, NASDAL lawyers hope to take several weeks off the process as well as reduce the legal costs.

Clients' wishes will always be respected by NASDAL and essential features such as maintenance contracts, pressure vessel testing insurance certificates, hepatitis B certificates and the myriad other essential aspects of a sale will be there in the contract from the start. Reader response number 55

\section{TAKING THE LEAD IN SURGERY DESIGN}

Takara Belmont and SPS Dental have forged an alliance to provide equipment to ten dental surgeries within the Olympic villages for the 2012 Games.

Whether competitors are swimming in London, sailing in Weymouth or rowing in Tenby, their dental needs will be addressed with the utmost professionalism and haste in all of these venues. They can rest assured

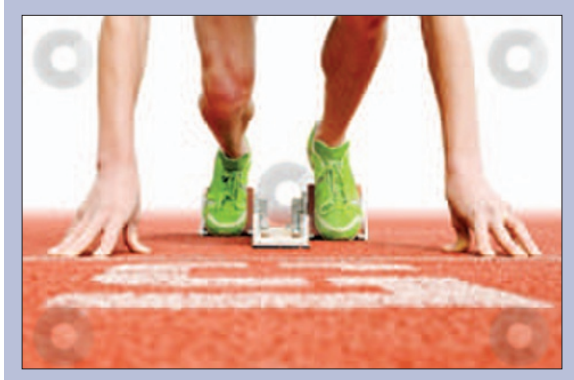

that any treatment at these venues will take place in the comfort of Takara Belmont's Voyager II-L Treatment Centre.

Relaxing in a Voyager, any patient's journey toward better dental health is smoother and more pleasant, allowing them the freedom of mind to focus on their competition.

This Treatment Centre sets the benchmark for quality and reliability, while simultaneously being of great value. Its ambidextrous design provides equal right and left compatibility for dental professionals and outstanding ergonomics allow for a space saving and efficient working environment.

Reader response number 56

\section{ADVANCED IMPLANTOLOGY COURSE}

Implantologists can gain the

confidence to tackle complex cases

on an advanced course featuring live surgery and hands-on training. 'Sinus Augmentation and Bone Grafting' is presented by Dr Nadir Khan and Dr Tushar Patel at Colchester Dental Referral Centre twice during 2012. Delegates assist with patient treatment and practise procedures on sheep's skulls and pigs' mandibles.

The two-day programme from Dentsply Friadent is designed for implantologists who wish to understand the management of difficult cases with compromised bone. The content includes demonstrations of bone grafting, sinus floor management and soft tissue grafting, with or without simultaneous implant placement.

Colchester Dental Referral Centre is a purpose-designed, multidisciplinary, specialist referral centre. The Sinus Augmentation and Bone Grafting course will run on 18-19 April and 17-18 October 2012 and group size will

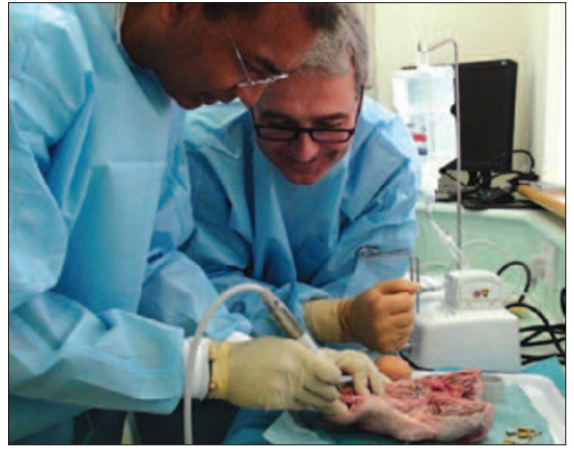

be limited to six to allow maximum interaction.

Reader response number 57 